\title{
Perfil de aglutininas anti-Leptospira em bezerras búfalas vacinadas com bacterina pentavalente comercial contra leptospirose
}

\author{
[Serological response anti-Leptospira in female buffalo calves vaccinated with commercial \\ pentavalent bacterin against leptospirosis] \\ G. Nardi Júnior ${ }^{1}$, M.G. Ribeiro ${ }^{1}$, S.A. Vasconcellos $^{2}$, J. Megid ${ }^{1}$, A.M. Jorge ${ }^{1}$, \\ L. Geronutti ${ }^{1}$, Z.M. Morais $^{2}$ \\ ${ }^{1}$ Faculdade de Medicina Veterinária e Zootecnia - UNESP \\ Caixa Postal 560 \\ 18618-000 - Botucatu, SP \\ ${ }^{2}$ FMVZ - USP - São Paulo, SP
}

\begin{abstract}
RESUMO
Avaliou-se o perfil sorológico de 17 bezerras búfalas vacinadas nos dias zero, 30 e 210 com bacterina pentavalente comercial contra leptospirose, empregando-se a prova de soroaglutinação microscópica com antígenos vivos, durante o período de 360 dias. Utilizaram-se quatro bezerras-controle, e todos os animais foram negativos no dia zero. Nos animais vacinados, foram observadas reações aos 60 dias para todos os sorovares, associadas a títulos máximos para Canicola, Grippothyphosa e Pomona. No $90^{\circ}$ dia, houve declínio acentuado dos títulos para todos os sorovares e ausência de títulos para Hardjo. Nos dias $120^{\circ}$, $150^{\circ}, 180^{\circ}$ e $210^{\circ}$, ocorreram oscilações de títulos para todos os sorovares. No $240^{\circ}$ dia, foram encontrados títulos máximos para Hardjo, elevação para os outros sorovares e ausência de título para Canicola. Nos dias $270^{\circ}, 300^{\circ}$ e $330^{\circ}$, foi observado declínio gradativo dos títulos. No $360^{\circ}$ dia, foram encontrados títulos residuais para Icterohaemorrhagiae, Grippothyphosa e Pomona e ausência de reação para os outros sorovares. Inferiram-se a reduzida persistência dos títulos vacinais mesmo após o reforço e revacinação e a baixa interferência da vacinação no diagnóstico sorológico.
\end{abstract}

Palavras-chave: leptospirose, búfalo, soroaglutinação, vacinação, sorovar

\begin{abstract}
The serological profile of 17 buffalo calves vaccinated at zero, 30 and 210 days of age using a commercial pentavalent bacterin against leptospirosis was evaluated using microscopic seroagglutination, during 360 days post-vaccination (PV). Four non-vaccinated buffalo calves were used as control. All animals studied showed a negative reaction at day zero. In the vaccinated animals, the serological responses for all serovars were detected at the $60^{\text {th }}$ day $P V$, with maximum agglutinin levels for Canicola, Grippothyphosa and Pomona. The antibody levels decreased for all serovars at day 90 with zero titters for Hardjo serovar. At days 120, 150, 180 and 210 PV were observed oscillations of titters for all serovars. At day 240, maximum antibody levels for Hardjo, an increase of titters for others serovars and no reaction for Canicola were found. At days 270, 300 and 330 a gradual decrease of antibody levels were observed. At day 360 residual titters for Icterohaemorrhagiae, Grippothyphosa and Pomona, and no reaction for the other serovars were observed. The results indicate a short persistency of seric agglutinin levels induced by vaccination, even after improvement and preparation of the vaccine reinforcement, and low interference of vaccination with serodiagnosis.
\end{abstract}

Keywords: leptospirosis, buffalo, seroagglutination, vaccination, serovar

Recebido em 12 de maio de 2004

Aceito em 02 de março de 2006

*Autor para correspondência (corresponding author)

E-mail: mgribeiro@fmvz.unesp.br 


\section{INTRODUÇÃO}

As infecções por Leptospira sp na espécie bubalina comumente são determinadas pelos sorovares Hardjo, Wolffi, Pomona, Icterohaemorrhagiae, Canicola e Grippothyphosa (Radostits et al., 2000).

Nos bubalinos, assim como nos bovinos, o abortamento ocorre como seqüela de infecção sistêmica. Durante a fase de leptospiremia, há morte fetal com ou sem degeneração placentária, seguida de eliminação fetal algumas semanas após a infecção. Os abortamentos pelo gênero Leptospira em bubalinos e bovinos ocorrem geralmente no terço final da gestação (Radostits et al., 2000), e o sorovar Hardjo é reconhecido como o mais adaptado a essas espécies (Costa et al., 1998; Ellis, 1994). Uma vez introduzido no rebanho, esse sorovar estabelece níveis variáveis de infecção, podendo persistir por longos períodos (Hathaway et al., 1986).

A profilaxia da leptospirose em búfalos e bovinos inclui a adoção de diferentes procedimentos, como o controle de roedores, a eliminação do excesso de água estagnada no ambiente, o isolamento e a terapia de animais doentes, e a imunização sistemática dos animais (Guimarães et al., 1982/1983, Moreira, 1994).

As vacinas comumente disponíveis no comércio para a profilaxia da leptospirose em búfalos e em bovinos são produzidas a partir de culturas bacterianas totais inativadas (bacterinas) (Langoni et al., 1999), cuja eficácia aumenta com a incorporação de substâncias adjuvantes ao antígeno (Hanson, 1977). Em geral, o uso de vacinas contra leptospirose reduz a ocorrência da infecção, a severidade dos sintomas clínicos, os problemas reprodutivos (Bolin et al., 1989) e o impacto econômico da doença (Sullivan, 1974). A necessidade de revacinações é um fator preocupante na interpretação do sorodiagnóstico, em virtude de induzirem à formação de aglutininas pós-vacinais, dificultando a diferenciação de imunoglobulinas (Ig) de origem vacinal das provenientes de infecção (Freudenstein e Hein, 1991).

Apesar dessa dificuldade no diagnóstico sorológico em animais vacinados, são escassos os estudos conduzidos no acompanhamento sorológico de bubalinos infectados ou vacinados contra leptospirose. Rao e Keshavamurthy (1985) utilizaram a microtécnica de soroaglutinação microscópica (SAM) para avaliar a resposta imune de bezerros bubalinos vacinados com bacterina pentavalente contendo os sorovares Pomona, Canicola, Hebdomadis, Tarassovi e Shermani. A soroconversão vacinal foi observada no $15^{\circ}$ dia pós-vacinação. Os anticorpos contra os sorovares da vacina persistiram durante os três meses de acompanhamento dos animais. A melhor resposta foi obtida nos bezerros que receberam duas doses de vacina comparativamente àqueles que receberam dose única. Hanson (1977) avaliou a vacinação anual de rebanho bovino naturalmente infectado, observando declínio progressivo de aglutininas anti-Leptospira a partir de 12 meses da vacinação. No mesmo estudo, foi constatada a ausência de reações sorológicas para Leptospira sp sete anos após a vacinação.

Em virtude da relevância da leptospirose no contexto de saúde pública e da escassez de estudos que enfoquem o diagnóstico sorológico da doença em búfalos, o presente estudo objetivou investigar o perfil de aglutininas antiLeptospira em búfalas vacinadas contra leptospirose.

\section{MATERIAL E MÉTODOS}

O estudo foi realizado com 21 bezerras búfalas da raça Murrah e mestiças, entre quatro e cinco meses de idade. Nenhuma das bezerras havia sido vacinada contra leptospirose antes do início do estudo, assim como eram filhas de búfalas também não vacinadas contra a doença. Todas as bezerras foram mantidas a pasto, nas mesmas condições de manejo.

A vacina utilizada constitui-se de bacterina pentavalente comercial, contendo as seguintes variantes sorológicas: Hardjo, Pomona, Grippothyphosa, Icterohaemorrhagiae e Canicola. Todas as vacinações foram efetuadas com a mesma partida da vacina que foi conservada em temperatura de refrigeração (4 a 8 ${ }^{\circ} \mathrm{C}$ ), até o momento do uso.

Procedeu-se à vacinação de 17 bezerras búfalas, selecionadas aleatoriamente, utilizando-se $2,0 \mathrm{ml}$ da bacterina comercial, via intramuscular, nos 
dias zero (primo-vacinação), seguida de reforço com 30 dias e revacinação com 210 dias após a primo-vacinação. Quatro bezerras não foram vacinadas, formando o grupo-controle.

Previamente à primo-vacinação, foi realizada a colheita de sangue dos 21 animais, constituindo dia zero do estudo. As duas primeiras colheitas, subseqüentes ao dia zero, foram realizadas em intervalos de 15 dias, constituindo os dias $15^{\circ}$ e $30^{\circ}$ após a primo-vacinação. Em seguida, foram realizadas colheitas em intervalos de 30 dias, perfazendo os dias $60^{\circ}, 90^{\circ}, 120^{\circ}, 150^{\circ}, 180^{\circ}$, $210^{\circ}, 240^{\circ}, 270^{\circ}, 300^{\circ}, 330^{\circ}, 360^{\circ}$ de acompanhamento dos animais.

Os níveis de aglutininas anti-Leptospira foram avaliados utilizando-se a técnica de soroaglutinação microscópica (microtécnica) com antígenos vivos (SAM) (Faine et al., 1999), frente aos seguintes sorovares: Canicola, Icterohaemorrhagiae, Grippothyphosa, Pomona e
Hardjo. Foram considerados reagentes os animais que apresentaram título $\geq 100$.

Em virtude da obrigatoriedade da vacinação dos animais no setor de bubalinocultura utilizado, todos os animais foram vacinados (vacina comercial) contra brucelose (amostra B19) entre 90 e 120 dias de estudo. Ao final do acompanhamento, os animais foram vacinados contra febre aftosa.

\section{RESULTADOS}

A Fig. 1 sumariza o perfil de aglutininas nas fêmeas bubalinas vacinadas contra leptospirose ao longo de 360 dias de acompanhamento dos animais. Ao final do estudo, não foi observada qualquer reação vacinal de natureza local ou sistêmica. Os 21 animais estudados foram negativos na prova de SAM na amostragem obtida no momento da primeira vacinação (dia zero).

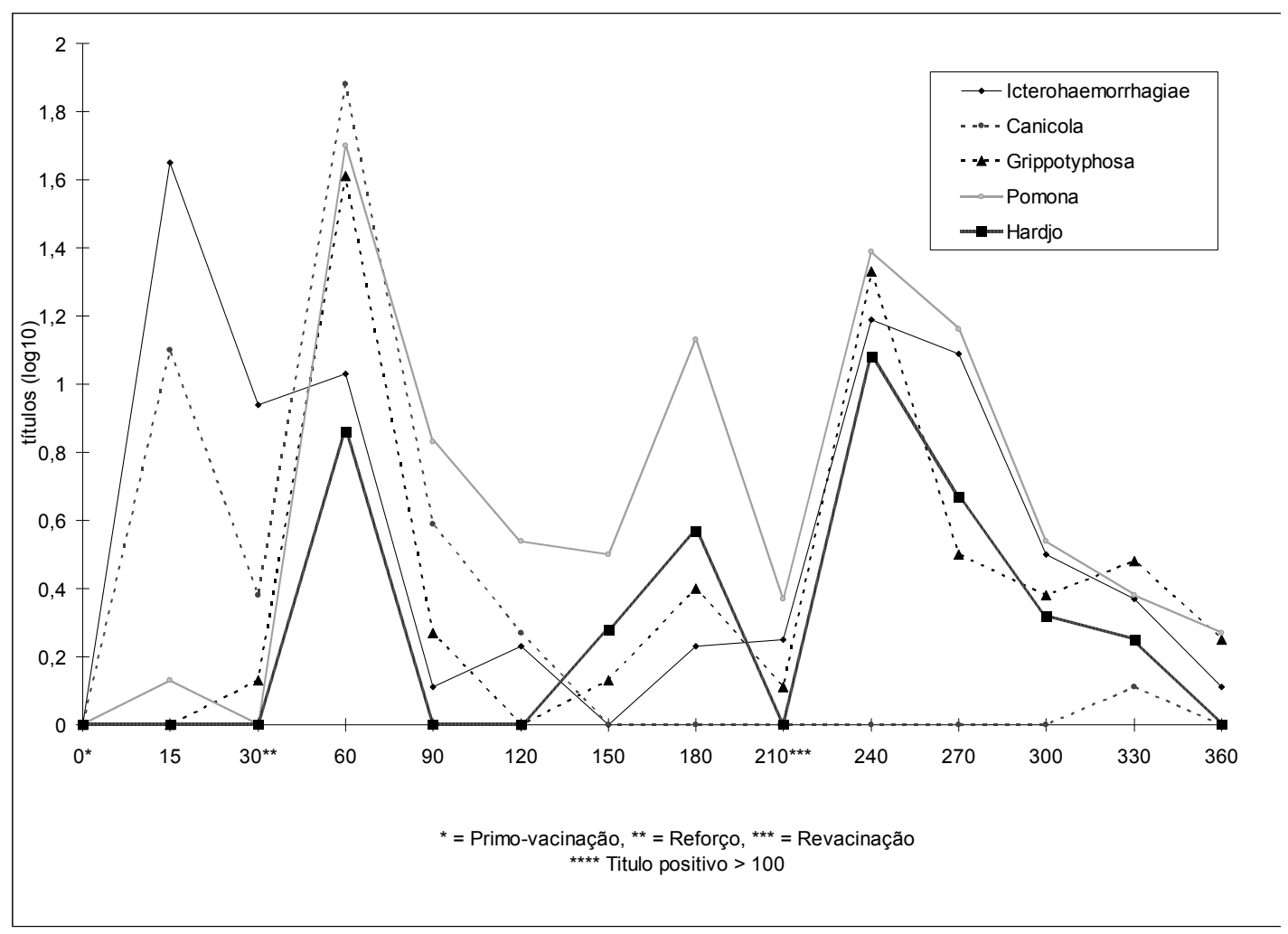

Figura 1. Média geométrica de aglutininas anti-Lepstopira na prova de soroaglutinação microscópica com antígenos vivos, para diferentes sorovares, em bezerras bubalinas vacinadas contra leptospirose. 
Aos 15 dias, após a primo-vacinação das 17 bezerras, foram observadas reações somente para os sorovares Canicola, Pomona e Icterohaemorrhagiae. No $15^{\mathrm{o}}$ dia, o sorovar Icterohaemorrhagiae atingiu o maior pico de título. No $30^{-}$dia após a vacinação (que coincidiu com o reforço vacinal), constatou-se declínio acentuado dos títulos para os sorovares Canicola e Icterohamorrhagiae, ausência de título para o sorovar Pomona e baixos títulos para o sorovar Grippothyphosa. O sorovar Hardjo permaneceu inalterado, com ausência de título em todos os animais vacinados.

Aos 60 dias (30 dias após o reforço vacinal), foram encontradas reações para todos os sorovares nos animais vacinados e títulos máximos alcançados no estudo para Canícola, Grippothyphosa e Pomona. No $90^{\circ}$ dia de acompanhamento dos animais vacinados, houve declínio acentuado dos títulos para os sorovares Canícola, Icterohaemorrhagiae, Grippothyphosa e Pomona, acompanhado de ausência de título para o sorovar Hardjo.

Nas colheitas realizadas nos dias $120^{\circ}, 150^{\circ}, 180^{\circ}$ e $210^{\circ}$ - essa última coincidindo com a revacinação -, foram observadas oscilações de títulos nos animais vacinados, com destaque para elevação dos sorovares Pomona e Hardjo aos 180 dias de estudo.

O $240^{\circ}$ dia de acompanhamento dos animais vacinados (30 dias após a revacinação) caracterizou-se por títulos máximos alcançados pelo sorovar Hardjo, acompanhado de elevação marcante dos títulos para todos os outros sorovares, com exceção do sorovar Canícola, que permaneceu com ausência de reação. Nas colheitas realizadas nos dias $270^{\circ}, 300^{\circ}$ e $330^{\circ}$ nos animais vacinados, foi evidenciado $o$ declínio gradativo dos títulos para os diferentes sorovares, com exceção do sorovar Canícola, que apresentou oscilação de título, voltando a reagir para um animal, no $330^{\circ}$ dia. Ao final dos $360^{\circ}$ dias de acompanhamento dos animais vacinados, os sorovares Icterohaemorrhagiae, Grippothyphosa e Pomona ainda apresentavam títulos residuais, enquanto os demais sorovares caracterizaram-se pela ausência de reação.

Os quatro animais não vacinados (controle) tenderam a apresentar, ao longo do estudo, ausência de reação para os sorovares utilizados, com exceção de um animal que, aos 60 dias de acompanhamento, reagiu para os sorovares Canicola, Icterohaemorrhagiae e Pomona, e, no $270^{\circ}$ dia, para o sorovar Icterohaemorrhagiae.

\section{DISCUSSÃO E CONCLUSÕES}

A vacinação contra leptospirose é considerada um dos mais importantes procedimentos de controle da doença em animais de produção. Entretanto, a menor imunidade conferida pelas bacterinas (Tizard, 1998) disponíveis comercialmente para vacinação de búfalos requer $\mathrm{o}$ inconveniente de reforços vacinais $\mathrm{e}$ revacinações, que podem dificultar a diferenciação de $\mathrm{Ig}$ de origem vacinal das Ig oriundas de infecção em provas sorológicas de rotina (Hanson, 1977; Freudenstein e Hein, 1991).

A primo-vacinação das bezerras búfalas com bacterina pentavalente comercial induziu resposta sorológica inicial para todos os sorovares contidos na vacina, com exceção do sorovar Hardjo, que apresentou título somente após o reforço (30 dias). Nos animais-controle foi observada tendência de negatividade sorológica ao longo do estudo. $\mathrm{O}$ monitoramento sorológico das bezerras búfalas ao longo de 360 dias revelou títulos máximos e soroconversão para a maioria dos sorovares no $60^{\circ}$ dia de acompanhamento dos animais vacinados (30 dias após o reforço vacinal), com exceção dos sorovares Icterohaemorrhagiae e Hardjo, que apresentaram, respectivamente, títulos máximos no $15^{\circ}$ e $240^{\circ}$ após a primo-vacinação. Estes resultados são similares aos encontrados por Nardi Júnior et al. (2003), no Brasil, que também evidenciaram títulos máximos para leptospirose na prova de soroaglutinação microscópica com antígenos vivos, entre 45 e 60 dias após a vacinação de 22 fêmeas bubalinas adultas, utilizando dois tipos de vacinas, administradas em duas doses, intercaladas com 30 dias.

Entre os dias $90^{\circ}$ e $210^{\circ}$, foi observada grande oscilação dos títulos nos animais vacinados, acompanhada de declínio abrupto de todos os sorovares, tendendo à negatividade 30 a 90 dias após o reforço vacinal (60 dias), com exceção do sorovar Pomona, que apresentou ascensão do título no $180^{\circ}$ dia. A ocorrência de oscilação de títulos entre os dias $90^{\circ}$ e $210^{\circ}$ de 
acompanhamento poderia decorrer de reações inespecíficas (cruzadas) entre os gêneros Leptospira e Brucella em provas sorológicas convencionais (Kadlec, 1978; Corbel, 1985), visto que esse período coincidiu com a vacinação das bezerras contra brucelose (amostra atenuada B19).

No $240^{\circ}$ dia de estudo (30 dias após a revacinação), foi constatada nova elevação do título para todos os sorovares, com exceção do sorovar Canicola, que permaneceu com ausência de reação. Em estudo similar, Nardi Júnior et al. (2003) também encontraram baixos títulos para o sorovar Canicola em bezerras búfalas vacinadas contra leptospirose com vacina polivalente comercial, mesmo após o reforço e as revacinações, sugerindo baixa resposta desse sorovar para espécie bubalina, mediante a avaliação de aglutininas pela prova de SAM.

Os títulos máximos observados após a revacinação (210 dias) foram de menor magnitude comparativamente ao observado após o reforço (60 dias), com exceção do sorovar Hardjo, que atingiu títulos máximos aos 240 dias de estudo. Apesar da maior produção de aglutininas anti-Leptospira encontrada após o reforço vacinal em detrimento da revacinação, o perfil dos títulos sorológicos nas 17 bezerras vacinadas caracterizou-se como de curta persistência. Nardi Júnior et al. (2003) também verificaram que o uso de vacina comercial polivalente contra leptospirose em bezerras búfalas induziu resposta sorológica fugaz na SAM, mesmo após o reforço e as revacinações. Estes resultados sugerem a necessidade de revacinações periódicas - a partir do reforço -, em intervalos entre quatro ou seis meses, visando otimizar a profilaxia vacinal na leptospirose em búfalos.

O sorovar Hardjo é assinalado em todo o mundo como um dos mais adaptados às espécies bubalina e bovina (Ellis, 1994; Costa et al., 1998; Radostits et al., 2000). No presente estudo, foi detectada soroconversão para esse sorovar somente após o reforço vacinal. Adicionalmente, os títulos observados para o sorovar Hardjo caracterizaram-se como fugazes e de baixa intensidade - em comparação aos outros sorovares contidos na vacina -, apresentando títulos máximos somente aos 240 dias de acompanhamento, 30 dias após a revacinação.
Ainda que não se credite relação direta entre os níveis de aglutininas séricas detectadas pela soroaglutinação microscópica com antígenos vivos e o nível de proteção conferido pela vacina (Hanson, 1977), os dados do presente estudo apontam para a precaução em se instituir protocolos vacinais que contemplem revacinações sucessivas, no intuito de alcançar melhores índices de proteção vacinal, especialmente para o sorovar Hardjo.

Ao final dos 360 dias de acompanhamento dos animais vacinados, os sorovares Pomona, Grippothyphosa e Icterohaemorrhagiae ainda apresentavam títulos residuais, de baixa intensidade. Entretanto, o declínio acentuado e a baixa persistência dos níveis de aglutininas antiLeptospira induzidos pela vacinação - não superiores a quatro meses para a maioria dos animais, mesmo após o reforço e a revacinação apontam para a baixa interferência da vacinação com bacterinas no sorodiagnóstico da leptospirose em búfalos, utilizando a microtécnica. Este resultado sugere a possibilidade de realização da soroaglutinação microscópica com antígenos vivos em búfalos vacinados com bacterinas, a partir de quatro meses da última dose de vacina, com baixo risco de interferência de Igs de origem vacinal na interpretação dos resultados sorológicos.

\section{REFERÊNCIAS BIBLIOGRÁFICAS}

BOLIN, C.A.; THIERMANN, A.B.; HANDSAKER, A.L. et al. Effect of vaccination with a pentavalent leptospiral vaccine on Leptospira interrogans serovar hardjo type hardjo-bovis infection of pregnant cattle. Am. J. Vet. Res., v.50, p.161-165, 1989.

CORBEL, M.J. Recent advances in the study of Brucella antigens and their serological crossreactions. Vet. Bull., v.55, p.927-942, 1985.

COSTA, M.C.R.; MOREIRA, E.C.; LEITE, R.C. et al. Avaliação da imunidade cruzada entre Leptospira hardjo e L. wolffi. Arq. Bras. Med. Vet. Zootec., v.50, p.11-17, 1998.

ELLIS, W.A. Leptospirosis as a cause of reproductive failure. Vet. Clin. North Am., v.10, p.463-478, 1994.

FAINE, S.; ADLER, B.; BOLIN, C. et al. leptospira and Leptospirosis. 2.ed. Melbourne: MediSci, 1999. 272p. 
FREUDENSTEIN, H.; HEIN, B. Potency of leptospiral vaccines and protection against chronic infection in golden hamsters. Comp. Immunol. Microbiol. Infect. Dis., v.14, p.229234, 1991

GUIMARÃES, M.C.; CÔRTES, J.A.; VASCONCELLOS, S.A. et al. Epidemiologia e controle de leptospirose em bovinos. Papel do portador e seu controle terapêutico. Comun. Ciên. Fac. Med. Vet. Zootec. USP, v.6/7, p. 2134, 1982/1983.

HANSON, L.E. Immunology of bacterial diseases, with special reference to leptospirosis. J. Am. Vet. Med. Assoc., v.170, p.991-994, 1977.

HATHAWAY, S.C.; LITTLE, T.W.A.; PRITCHARD, D.G. Problems associated with the serological diagnosis of Leptospira interrogans serovar hardjo infection in bovine populations. Vet. Rec., v.119, p.84-86, 1986.

KADLEK, V. Observation on the antigenic affinity of Leptospira and Brucella in the serological examination of cattle. Vet. Med. (Praha), v.23, p.213-218, 1978.

LANGONI, H.; DEL FAVA, C.; CABRAL, K.G. et al. Aglutininas antileptospíricas em búfalos do Vale do Ribeira, Estado de São Paulo. Ciênc. Rural, v.29, p.305-307, 1999.
MOREIRA, E.C. Avaliação de métodos para erradicação de leptospiroses em bovinos leiteiros. 1994. Tese (Doutorado) - Escola de Veterinária, Universidade Federal de Minas Gerais, Belo Horizonte.

NARDI JUNIOR, G.; GENOVEZ, M.E.; RIBEIRO, M.G. et al. Níveis de aglutininas antiLeptospira no soro de búfalas (Bubalus bubalis) vacinadas com dois tipos de vacinas comerciais anti-leptospirose. Resultados parciais. In: REUNIÃO ANUAL DO INSTITUTO BIOLÓGICO, 16., 2003, São Paulo. Anais... São Paulo, 2003 (CD-rom).

RADOSTITS, O.M.; GAY, C.C.; BLOOD, D.C. et al. Veterinary medicine. A textbook of the diseases of cattle, sheep, pigs, goats and horses. 9.ed. London: WB Saunders, 2000. p.971-996.

RAO, A.S.; KESHAVAMURTHY, B.S. Study of the immune response of buffalo calves to heatkilled pentavalent leptospiral vaccine. Indian Vet. J., v.62, p.357-361, 1985.

SULLIVAN, N.D. Leptospirosis in animals and man. Aust. Vet. J., v.50, p.216-223, 1974.

TIZARD, I.R. Imunologia veterinária. Uma introdução. 5.ed. São Paulo: Roca, 1998. p.273293. 